\title{
Prognostic impact of the ratio of the main pulmonary artery to that of the aorta on chest computed tomography in patients with idiopathic pulmonary fibrosis
}

\author{
Ji Soo Choi, Sang Hoon Lee, Ah. Young Leem, Joo Han Song, Kyung Soo Chung, Ji Ye Jung, Young Ae Kang, \\ Moo Suk Park, Young Sam Kim, Joon Chang and Song Yee Kim ${ }^{*}$
}

\begin{abstract}
Background: In many clinical disorders, there is a relationship between the ratio of the diameter of the main pulmonary artery (mPA) to that of the aorta (Ao) on chest computed tomography (CT). The aim of this study was to determine if the MPA/Ao ratio at diagnosis is associated with the clinical characteristics and outcomes in patients with idiopathic pulmonary fibrosis (IPF).

Methods: We retrospectively reviewed the diameters of the pulmonary artery and aorta on chest CT, clinical characteristics, and results of other examinations in 303 patients at the time of initial diagnosis of IPF at our tertiary care center between 2011 and 2015. The primary outcomes were death and lung transplantation. The patients were followed up until June 2017.

Results: One hundred and eight patients (35.6\%) died and 58 (19.1\%) underwent lung transplantation during follow-up. The mean mPA and Ao diameters were $28.3 \mathrm{~mm}$ and $34.0 \mathrm{~mm}$, respectively, and the mean mPA/Ao ratio was 0.84 . Thirty-one patients (10.2\%) had an mPA/Ao ratio $>1.0$ and 182 (60.1\%) had an MPA/Ao ratio > 0.8. Patients with an mPA/Ao ratio $>0.8$ had a lower DLco value than those with an mPA/Ao ratio $\leq 0.8$. In Kaplan-Meier analysis, patients with an $\mathrm{mPA} / \mathrm{Ao}$ ratio $>1.0$ or $>0.8$ had worse outcomes than those with an $\mathrm{mPA} / \mathrm{Ao}$ ratio $\leq 1.0$ and $\leq 0.8$, respectively.
\end{abstract}

Conclusions: A higher mPA/Ao ratio based on 1.0 and 0.8 is associated with unfavorable prognosis in patients with IPF.

Keywords: Pulmonary artery, Idiopathic pulmonary fibrosis, Prognosis

\section{Background}

Idiopathic pulmonary fibrosis (IPF) is a chronic, progressive, and fatal disease. The natural course of IPF can be diverse, and prediction of the prognosis is difficult. Pulmonary hypertension $(\mathrm{PH})$ is common in the advanced stages of IPF, and its presence is reported to be associated with decreased exercise capacity and high mortality in patients with IPF [1-3]. The definition of PH is based on data obtained by right heart catheterization [4], which is an invasive and costly procedure. Furthermore,

\footnotetext{
* Correspondence: dobie@yuhs.ac

Division of Pulmonology, Department of Internal Medicine, Severance Hospital, Yonsei University College of Medicine, 50 Yonsei-ro, Seodaemun-gu, Seoul 03722, Republic of Korea
}

transthoracic echocardiography is known to be a useful noninvasive method when screening for $\mathrm{PH}[5,6]$ but is also a costly method and has limited accuracy for assessment of $\mathrm{PH}$ in patients with IPF $[7,8]$.

Measurement of the diameter of the main pulmonary artery (mPA) on CT of the chest has been reported to predict the presence of $\mathrm{PH}$ in patients with parenchymal lung disease, such as IPF or chronic obstructive pulmonary disease (COPD) [9-12], and the ratio of the diameter of the $\mathrm{mPA}$ to that of the aorta $(\mathrm{Ao})>1$ has been reported to indicate a very high probability of $\mathrm{PH}[13]$. Furthermore, in a previous study conducted in the US, an $\mathrm{mPA} /$ Ao ratio $>1$ was associated with worse outcomes in patients with IPF, and measurement of the 
$\mathrm{mPA} /$ Ao ratio on chest $\mathrm{CT}$ assisted in evaluation of the risk and prognosis in these patients [14]. However, another study reported that the diameter of the mPA, that of the Ao, and the $\mathrm{mPA} / \mathrm{Ao}$ ratio can vary according to ethnicity and lifestyle [15], implying that the $\mathrm{mPA} /$ Ao ratio may be different in Asian patients with IPF from that in their Western counterparts. The aim of this study was to determine if there is an association of the mPA/Ao ratio with clinical characteristics and outcomes in Korean patients with IPF.

\section{Methods}

\section{Study design}

We retrospectively identified 460 patients who were diagnosed or referred with IPF at our tertiary care university hospital in South Korea between January 2011 and December 2015. The diagnosis was confirmed clinically in 296 patients and pathologically in 164 patients by consensus among multidisciplinary specialists according to the 2011 American Thoracic Society/European Respiratory Society/Japanese Respiratory Society/Latin American Thoracic Association guidelines [2]. One hundred and fifty-seven patients who did not attend for follow-up after diagnosis were excluded, leaving data for 303 patients with IPF available for inclusion in the analysis.

The patients' initial CT scans of the chest and medical records, including baseline characteristics, laboratory findings, 6-min walking distance, pulmonary function test (PFT) results at the time of diagnosis, and echocardiographic findings were reviewed to evaluate their associations with the mPA/Ao ratio. The primary outcomes were death and lung transplantation. The study protocol was approved by the institutional review board at Severance Hospital (IRB 4-2017-1219) and the need for informed consent was waived.

\section{Measurements}

CT scans of the chest were performed in all the patients at the time of initial diagnosis of IPF. The diameter of the mPA and that of the ascending Ao were measured at the level of bifurcation of the pulmonary artery. The diameter of the MPA was defined as the widest diameter perpendicular to the long axis of the mPA and measurement of the ascending Ao was taken as the transverse diameter (Fig. 1). Two reviewers who were blinded to the clinical data measured the MPA and Ao on the same CT image independently, and the average of two measurements was used to calculate the MPA/Ao ratio. The value of inter-observer correlation coefficient was 0.84 (95\% confidence interval (CI), 0.80-0.87) for mPA, and 0.92 (95\% CI, 0.90-0.94) for Ao.

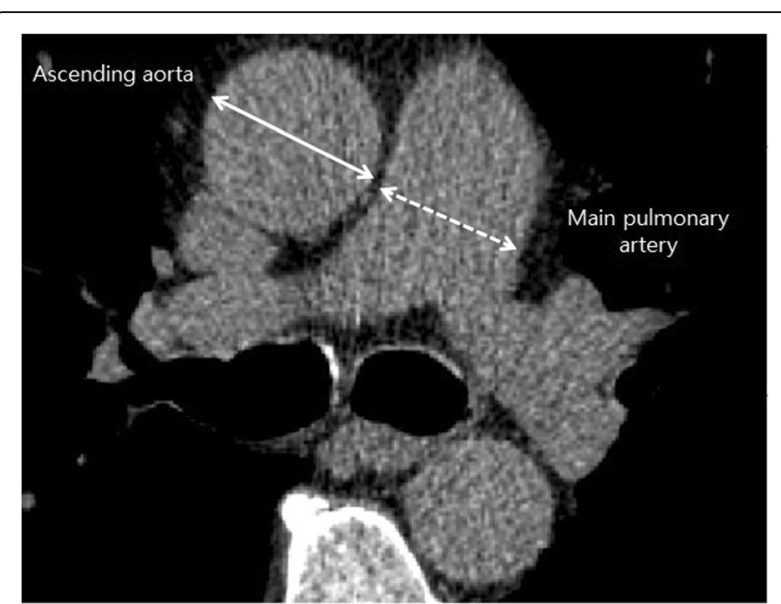

Fig. 1 Measurement of the main pulmonary artery (mPA) and ascending aorta (Ao) diameters at the level of bifurcation of the pulmonary artery. The diameter of the MPA was defined as the widest diameter perpendicular to the long axis of the MPA and measurement of the ascending Ao was taken as the transverse diameter

We divided the patients into two groups according to whether they had an $\mathrm{mPA} / \mathrm{Ao}$ ratio $\leq 1$ or $>1$ on the initial chest CT. An mPA/Ao ratio $>1$ was considered to indicate the presence of $\mathrm{PH}$ [13]. The patients were then grouped according to whether the $\mathrm{mPA} / \mathrm{Ao}$ ratio was $\leq 0.8$ or $>0.8$ because of a previous report indicating that Korean patients with COPD and an mPA/Ao ratio $>0.8$ had clinical characteristics that differed from those in their counterparts with an $\mathrm{mPA} /$ Ao ratio $\leq 0.8$ [16].

\section{Statistical analysis}

The statistical analysis was performed using IBM SPSS version 23.0 software (IBM Corp., Armonk, NY, USA). Categorical variables are presented as the frequency and percentage and continuous variables as the median if the distribution was normal and as the interquartile range (IQR) if the distribution was non-normal. The GAP score, which includes sex, age, forced vital capacity (FVC) \% predicted, and diffusing capacity of the lung for carbon dioxide $\left(\mathrm{DL}_{\mathrm{CO}}\right) \%$ predicted [17] was calculated for each patient. The clinical characteristics of patients with a high $\mathrm{mPA} /$ Ao ratio and those with a low $\mathrm{mPA} / \mathrm{Ao}$ ratio using cutoff values of 1 and 0.8 were compared by logistic regression analysis and the results are presented as the odds ratio and $95 \%$ confidence interval (CI). The primary outcomes were evaluated using Kaplan-Meier curve analysis. The association of the MPA/Ao ratio with the outcome was analyzed by multivariate analysis using a Cox proportional hazards model, and the results are presented as the hazard ratio (HR) and 95\% CI. P-values $\leq .05$ were considered to be statistically significant. 


\section{Results}

\section{Baseline characteristics}

Table 1 shows the baseline characteristics of the enrolled patients, who comprised 234 men (77.2\%) and 69 women $(22.8 \%)$ of mean age $67.2 \pm 9.5$ years. Two hundred and one patients (69.6\%) were current or former smokers; these patients had a median 30-pack-year smoking history. The most common comorbidities were hypertension (33.0\%) and diabetes mellitus (29.0\%), followed by pulmonary tuberculosis (13.2\%) and emphysema (12.9\%). Less common diseases included ischemic heart disease (9.6\%) and congestive heart failure (3.3\%).

The median GAP score was 3.0 (IQR 2.0-4.0) and the median 6-min walking distance was $400 \mathrm{~m}$ (IQR 308.5-480.0). The median FVC \%, forced expiratory volume in $1 \mathrm{~s}\left(\mathrm{FEV}_{1}\right) \%$, and $\mathrm{FEV}_{1} / \mathrm{FVC}$ ratio were 74.0, 88.0, and 83.0, respectively. The median DLco \% was 69.0 (IQR 51.0-86.0). The median mPA, Ao, and
$\mathrm{mPA} / \mathrm{Ao}$ ratio values were $27.9 \mathrm{~mm}$ (IQR 26.1-30.5), $34.2 \mathrm{~mm}$ (IQR 31.6-36.7), and 0.83 (IQR 0.77-0.90), respectively.

\section{Clinical characteristics according to $\mathrm{MPA} /$ Ao ratio}

Table 2 shows the clinical characteristics of the patients according to whether the $\mathrm{mPA} / \mathrm{Ao}$ ratio was $\leq 1$ or $>1$. Thirty-one patients (10.2\%) had an mPA/Ao ratio $>1.0$. The median mPA diameter was $27.6 \mathrm{~mm}$ in the group with an $\mathrm{mPA} / \mathrm{Ao}$ ratio $\leq 1$ and $32.9 \mathrm{~mm}$ in the group with an $\mathrm{mPA} /$ Ao ratio $>1$. There was no difference in body mass index or smoking history between two groups. Right ventricular pressure and GAP score values were significantly higher in the group with an $\mathrm{mPA} /$ Ao ratio $>1$ in univariate analysis but not in multivariate analysis.

Table 3 shows the clinical characteristics of the patients according to whether the $\mathrm{mPA} / \mathrm{Ao}$ ratio was

Table 1 Baseline characteristics of patients with idiopathic pulmonary fibrosis

\begin{tabular}{|c|c|}
\hline Clinical characteristics & $n=303$ \\
\hline Age, years & $67.2 \pm 9.5$ \\
\hline Male sex & $234(77.2 \%)$ \\
\hline $\mathrm{BMI}, \mathrm{kg} / \mathrm{m}^{2}$, median (IQR) & $22.7(20.1-24.9)$ \\
\hline Ever-smoker & $211(69.6 \%)$ \\
\hline Smoking, pack-years, median (IQR) & $30.0(20.0-42.0)$ \\
\hline \multicolumn{2}{|l|}{ Underlying disease } \\
\hline Hypertension & $100(33.0 \%)$ \\
\hline Diabetes mellitus & $88(29.0 \%)$ \\
\hline Pulmonary tuberculosis & $43(13.2 \%)$ \\
\hline Emphysema & 39 (12.9\%) \\
\hline Ischemic heart disease & $29(9.6 \%)$ \\
\hline Congestive heart failure & $10(3.3 \%)$ \\
\hline GAP score, median (IQR) & $3.0(2.0-4.0)$ \\
\hline 6MWD, m, median (IQR) & $400.0(308.5-480.0)(N=152)$ \\
\hline \multicolumn{2}{|l|}{ Pulmonary function at diagnosis } \\
\hline FVC, \%, median (IQR) & $74.0(59.0-86.0)$ \\
\hline $\mathrm{FEV}_{1}, \%$, median (IQR) & $88.0(71.0-100.0)$ \\
\hline $\mathrm{FEV}_{1} / \mathrm{FVC}, \%$, median (IQR) & $83.0(77.8-89.0)$ \\
\hline $\mathrm{DL}_{\mathrm{CO}} \%$ & $69.0(51.0-86.0)$ \\
\hline \multicolumn{2}{|l|}{ Echocardiography } \\
\hline Ejection fraction \%, median (IQR) & $66.0(61.0-70.0)(N=196)$ \\
\hline Right ventricular pressure, mmHg, median (IQR) & $28.0(28.0-47.0)(N=163)$ \\
\hline \multicolumn{2}{|l|}{ Chest $C T$} \\
\hline mPA diameter, mm, median (IQR) & $27.9(26.1-30.5)$ \\
\hline Ascending Ao diameter, mm, median (IQR) & $34.2(31.6-36.7)$ \\
\hline mPA/Ao ratio, median (IQR) & $0.83(0.77-0.90)$ \\
\hline
\end{tabular}

The data are presented as the number (percentage) unless otherwise indicated. 6MWD, 6-min walking distance Ao aorta, BMI body mass index, $C T$ computed tomography, $D L_{C O}$ diffusing capacity of the lung for carbon dioxide, $F E V V_{1}$ forced expiratory volume in $1 \mathrm{~s}$, FVC forced vital capacity, IQR interquartile range, $M P A$ main pulmonary artery 
Table 2 Clinical characteristics of patients with idiopathic pulmonary fibrosis and a main pulmonary artery to aorta diameter ratio $\leq$ 1 and $>1$

\begin{tabular}{|c|c|c|c|c|c|c|c|c|}
\hline \multirow[t]{2}{*}{ Clinical factors } & \multicolumn{2}{|l|}{$\mathrm{mPA} / \mathrm{Ao}$ ratio } & \multicolumn{3}{|c|}{ Univariable analysis } & \multicolumn{3}{|c|}{ Multivariable analysis } \\
\hline & $\leq 1(n=272)$ & $>1(n=31)$ & OR & $95 \% \mathrm{Cl}$ & $P$ & $\mathrm{OR}$ & $95 \% \mathrm{Cl}$ & $P$ \\
\hline Age, years & $67.9 \pm 9.1$ & $60.4 \pm 10.0$ & 0.92 & $0.89-0.96$ & $<0.001$ & & & \\
\hline Sex, male & $215(79.0 \%)$ & $19(61.3 \%)$ & 2.38 & $1.09-5.19$ & 0.029 & & & \\
\hline BMI, kg/m² (median, IQR) & $22.7(20.2-24.9)$ & $22.5(19.1-26.2)$ & 1.01 & $0.91-1.12$ & 0.848 & & & \\
\hline Ever-smoker & 194 (71.9\%) & $17(54.8 \%)$ & 0.48 & $0.22-1.01$ & 0.054 & & & \\
\hline \multicolumn{9}{|l|}{ Underlying disease } \\
\hline Hypertension & $94(34.6 \%)$ & $6(19.4 \%)$ & 0.45 & $0.18-1.15$ & 0.095 & & & \\
\hline Diabetes mellitus & $82(30.1 \%)$ & $6(19.4 \%)$ & 0.56 & $0.22-1.41$ & 0.215 & & & \\
\hline Pulmonary tuberculosis & $41(15.1 \%)$ & $2(6.5 \%)$ & 0.39 & $0.09-1.69$ & 0.208 & & & \\
\hline Emphysema & $37(13.7 \%)$ & $2(6.5 \%)$ & 0.44 & $0.10-1.91$ & 0.270 & & & \\
\hline Ischemic heart disease & $28(10.3 \%)$ & $1(3.2 \%)$ & 0.29 & $0.04-2.21$ & 0.233 & & & \\
\hline Congestive heart failure & $10(3.7 \%)$ & $0(0 \%)$ & & & & & & \\
\hline GAP score & $3.11 \pm 1.24$ & $3.75 \pm 1.26$ & 1.57 & $1.08-2.27$ & 0.018 & 1.53 & $0.69-3.40$ & 0.298 \\
\hline $6 \mathrm{MW}$ distance, m (median, IQR) & $410.0(322.5-480.0)$ & $232.5(95.0-555.8)$ & 0.99 & $0.99-1.00$ & 0.032 & 0.99 & $0.99-1.00$ & 0.190 \\
\hline \multicolumn{9}{|l|}{ PFT at diagnosis } \\
\hline FVC, \% predicted, (median, IQR) & $75.0(61.0-86.3)$ & $55.0(44.5-72.0)$ & 0.95 & $0.93-0.98$ & $<0.001$ & & & \\
\hline $\mathrm{FEV}_{1}, \%$ predicted, (median, IQR) & $89.5(73.0-100.0)$ & $64.0(51.5-81.0)$ & 0.96 & $0.95-0.98$ & $<0.001$ & 1.07 & $0.99-0.15$ & 0.074 \\
\hline $\mathrm{DL}_{\mathrm{CO}}, \%$ & $70.9 \pm 23.8$ & $48.4 \pm 23.1$ & 0.96 & $0.94-0.98$ & $<0.001$ & & & \\
\hline \multicolumn{9}{|l|}{ Echocardiography } \\
\hline EF, \%, (median, IQR) & $65.0(61.0-69.0)$ & $67.0(64.0-71.0)$ & 1.08 & $1.01-1.14$ & 0.022 & 1.09 & $0.93-1.27$ & 0.285 \\
\hline RVP, mmHg, (median, IQR) & $37.0(27.8-46.0)$ & $43.0(33.0-52.5)$ & 1.03 & $1.01-1.06$ & 0.014 & 1.04 & $0.99-1.10$ & 0.113 \\
\hline \multicolumn{9}{|l|}{ Chest $C T$} \\
\hline mPA diameter, mm, (median, IQR) & $27.6(25.8-29.8)$ & $32.9(29.8-35.1)$ & 1.38 & $1.23-1.54$ & $<0.001$ & & & \\
\hline Ascending Ao diameter, mm, (median, IQR) & $34.5(32.0-36.9)$ & $29.8(27.7-32.8)$ & 0.71 & $0.62-0.80$ & $<0.001$ & & & \\
\hline
\end{tabular}

The data are presented as the number (percentage) unless otherwise indicated. 6MWD, 6-min walking distance

Ao aorta, $B M I$ body mass index, $C l$ confidence interval, $D L_{C O}$ diffusing capacity, $E F$ ejection fraction, $F E V_{1}$ forced expiratory volume in $1 \mathrm{~s}$, $F V C$ forced vital capacity, $I Q R$ interquartile range, $M P A$ main pulmonary artery, OR odds ratio, PFT pulmonary function tests, RVP right ventricular pressure

$\leq 0.8$ or $>0.8$. One hundred and eighty-two patients (60.1\%) had an $\mathrm{mPA} /$ Ao ratio $>0.8$. The median $\mathrm{mPA}$ diameter was $26.3 \mathrm{~mm}$ in the group with an mPA/Ao ratio $\leq 0.8$ and $29.7 \mathrm{~mm}$ in the group with an $\mathrm{mPA} / \mathrm{Ao}$ ratio $>0.8$. In multivariate analysis, the $\mathrm{DL}_{\mathrm{CO}}$ was lower in the group with an $\mathrm{mPA} / \mathrm{Ao}$ ratio $>0.8$ (odds ratio $0.97,95 \%$ CI $0.95-0.99, P=.003)$. There was no significant difference in patient age, $\mathrm{FVC}, \mathrm{FEV}_{1}$, or echocardiographic findings between the two groups.

\section{Outcomes of IPF and associated risks}

One hundred and eight patients (35.6\%) died and 58 (19.1\%) underwent lung transplantation during the follow-up period. The adjusted hazard ratios from the Cox proportional hazards analysis are shown in Table 4. A lower body mass index (HR 0.93; 95\% CI 0.89-0.97; $P<.001$ ), a higher GAP score (HR 1.68; 95\% CI 1.22-2.31; $P=.002$ ), and a higher $\mathrm{mPA} /$ Ao ratio (HR 3.06; $95 \% \mathrm{CI}$ $1.85-5.07 ; P<.001)$ were significantly associated with a poor prognosis, including death and lung transplantation, in patients with IPF.

Kaplan-Meier analysis of time to death or lung transplantation revealed that patients with an mPA/Ao ratio $>1.0$ had a worse outcome than those with an $\mathrm{mPA} / \mathrm{Ao}$ ratio $\leq 1.0$. Furthermore, the patients with an $\mathrm{mPA} /$ Ao ratio $>0.8$ had a worse outcome than those with an $\mathrm{mPA} /$ Ao ratio $\leq 0.8(P=.003$; Fig. 2$)$.

\section{Discussion}

The results of this study indicate that an $\mathrm{mPA} /$ Ao ratio $>1$ is associated with worse outcomes, including death and lung transplantation, in patients with IPF. An mPA/Ao ratio $>0.8$, which was the median value in patients with IPF, was also associated with a poor outcome.

IPF is a specific form of chronic and progressive fibrosing interstitial pneumonia of unknown cause, with a reported annual incidence of $0.8-76.4$ per 100,000 population $[18,19]$ and presents as progressive 
Table 3 Clinical characteristics of patients with idiopathic pulmonary fibrosis and a main pulmonary artery to aorta diameter ratio $\leq$ 0.8 and $>0.8$

\begin{tabular}{|c|c|c|c|c|c|c|c|c|}
\hline \multirow[t]{2}{*}{ Clinical factors } & \multicolumn{2}{|l|}{$\mathrm{mPA} / \mathrm{Ao}$ ratio } & \multicolumn{3}{|c|}{ Univariate analysis } & \multicolumn{3}{|c|}{ Multivariate analysis } \\
\hline & $\leq 0.8(n=121)$ & $>0.8(n=182)$ & OR & $95 \% \mathrm{Cl}$ & $P$ & OR & $95 \% \mathrm{Cl}$ & $P$ \\
\hline Age, years & $68.7 \pm 8.3$ & $66.1 \pm 10.0$ & 0.97 & $0.95-1.00$ & 0.019 & 0.96 & $0.91-1.01$ & 0.136 \\
\hline Sex, male & $102(84.3 \%)$ & $132(72.5 \%)$ & 2.03 & $1.13-3.66$ & 0.018 & & & \\
\hline $\mathrm{BMI}, \mathrm{kg} / \mathrm{m}^{2}$, (median, IQR) & $23.2(20.8-26.6)$ & $22.4(19.8-24.8)$ & 0.96 & $0.91-1.03$ & 0.247 & & & \\
\hline Ever-smoker & $91(75.8 \%)$ & $120(66.3 \%)$ & 0.63 & $0.37-1.05$ & 0.078 & & & \\
\hline \multicolumn{9}{|l|}{ Underlying disease } \\
\hline Hypertension & $40(33.1 \%)$ & $60(33.0 \%)$ & 1.00 & $0.61-1.62$ & 0.987 & & & \\
\hline Diabetes mellitus & $30(24.8 \%)$ & 58 (31.9\%) & 1.42 & $0.85-2.38$ & 0.185 & & & \\
\hline Pulmonary tuberculosis & $15(12.4 \%)$ & $28(15.4 \%)$ & 1.29 & $0.66-2.52$ & 0.466 & & & \\
\hline Emphysema & $19(15.7 \%)$ & $20(11.0 \%)$ & 0.67 & $0.34-1.31$ & 0.240 & & & \\
\hline Ischemic heart disease & $8(6.6 \%)$ & $21(11.5 \%)$ & 1.84 & $0.79-4.31$ & 0.158 & & & \\
\hline Congestive heart failure & $2(1.7 \%)$ & $8(4.4 \%)$ & 2.74 & $0.57-13.1$ & 0.208 & & & \\
\hline GAP score & $3.07 \pm 1.16$ & $3.24 \pm 1.31$ & 1.12 & $0.91-1.37$ & 0.280 & & & \\
\hline $6 \mathrm{MW}$ distance, m (median, IQR) & $415.0(356.3-477.5)$ & $400.0(246.3-480.0)$ & 0.99 & $0.99-1.00$ & 0.107 & & & \\
\hline \multicolumn{9}{|l|}{ PFT at diagnosis } \\
\hline FVC, \% predicted, (median, IQR) & $77.0(63.0-90.5)$ & $71.0(55.0-83.0)$ & 0.98 & $0.96-0.99$ & $<0.001$ & 1.01 & $0.97-1.05$ & 0.735 \\
\hline $\mathrm{FEV}_{1}, \%$ predicted, (median, IQR) & $94.0(76.0-101.0)$ & $83.0(66.0-98.5)$ & 0.98 & $0.97-0.99$ & $<0.001$ & 1.01 & $0.97-1.04$ & 0.805 \\
\hline $\mathrm{DL}_{\mathrm{CO}}, \%$ & $77.1 \pm 23.6$ & $62.7 \pm 23.6$ & 0.97 & $0.96-0.99$ & $<0.001$ & 0.97 & $0.95-0.99$ & 0.002 \\
\hline \multicolumn{9}{|l|}{ Echocardiography } \\
\hline EF, \%, (median, IQR) & $64.0(60.0-69.0)$ & $66.0(62.0-70.0)$ & 1.02 & $0.99-1.05$ & 0.294 & 1.16 & $0.93-1.45$ & 0.187 \\
\hline RVP, mmHg, (median, IQR) & $34.4(25.0-43.0)$ & $40.0(31.5-48.0)$ & 1.03 & $1.00-1.05$ & 0.038 & 1.01 & $0.98-1.05$ & 0.485 \\
\hline \multicolumn{9}{|l|}{ Chest CT } \\
\hline mPA diameter, mm, (median, IQR) & $26.3(24.5-27.9)$ & $29.7(27.1-31.9)$ & 1.49 & $1.34-1.65$ & $<0.001$ & & & \\
\hline $\begin{array}{l}\text { Ascending aorta diameter, } \\
\mathrm{mm} \text {, (median, IQR) }\end{array}$ & $35.7(33.9-37.7)$ & $32.7(30.4-35.0)$ & 0.75 & $0.69-0.82$ & $<0.001$ & & & \\
\hline
\end{tabular}

The data are presented as the number (percentage) unless otherwise indicated. 6MWD, 6-min walking distance Ao aorta, $C T$ computed tomography, $D L_{C O}$ diffusing capacity, EF ejection fraction, $F E V_{1}$ forced expiratory volume in $1 \mathrm{~s}, F V C$ forced vital capacity, $I Q R$ interquartile range, $M P A$ main pulmonary artery, $P F T$ pulmonary function test, $R V P$ right ventricular pressure

aggravation of dyspnea and decreasing lung function. The prognosis for patients with IPF is poor, with a median survival of $2.5-3.5$ years [2, 20,21]. PH is common in patients with IPF and is also associated with an increased risk of death and a poor outcome [22-24]. In a previous study, the prevalence of $\mathrm{PH}$ in patients with IPF listed for lung transplantation was $32 \%$ by right heart catheterization, and there was a linear correlation

Table 4 Clinical characteristics associated with death or lung transplantation in patients with idiopathic pulmonary fibrosis (multivariate analysis)

\begin{tabular}{llll}
\hline Variable & Hazard ratio & $95 \% \mathrm{Cl}$ & $P$-value \\
\hline BMl, $\mathrm{kg} / \mathrm{m}^{2}$ & 0.925 & $0.887-0.965$ & $<0.001$ \\
GAP score & 1.676 & $1.218-2.306$ & 0.002 \\
mPA/Ao ratio & 3.062 & $1.849-5.071$ & $<0.001$ \\
\hline
\end{tabular}

$A$ aorta, $B M I$ body mass index, $C l$ confidence interval, $m P A$ main pulmonary artery between the mortality risk and mean pulmonary artery pressure [1].

In our study, univariate analysis revealed a relationship between a higher $\mathrm{mPA} / \mathrm{Ao}$ ratio and a higher right ventricular pressure in patients with IPF. Although we could not perform right heart catheterization as part of our study, a higher right ventricular pressure is a known manifestation of $\mathrm{PH}[25,26]$, so an association between the $\mathrm{mPA} / \mathrm{Ao}$ ratio and PH is likely in patients with IPF. This finding is similar to those in previous studies in other pulmonary diseases $[7,9,27,28]$. Iyer et al. reported that an $\mathrm{mPA} / \mathrm{Ao}$ ratio $>1$ on a CT scan in patients with COPD correlated with invasive measurements of pulmonary artery pressure and the presence of $\mathrm{PH}$ [29]. Schmidt et al. also reported that estimation of pulmonary artery diameter on chest CT could predict the presence of $\mathrm{PH}$ in patients with chronic pulmonary embolism [30]. 


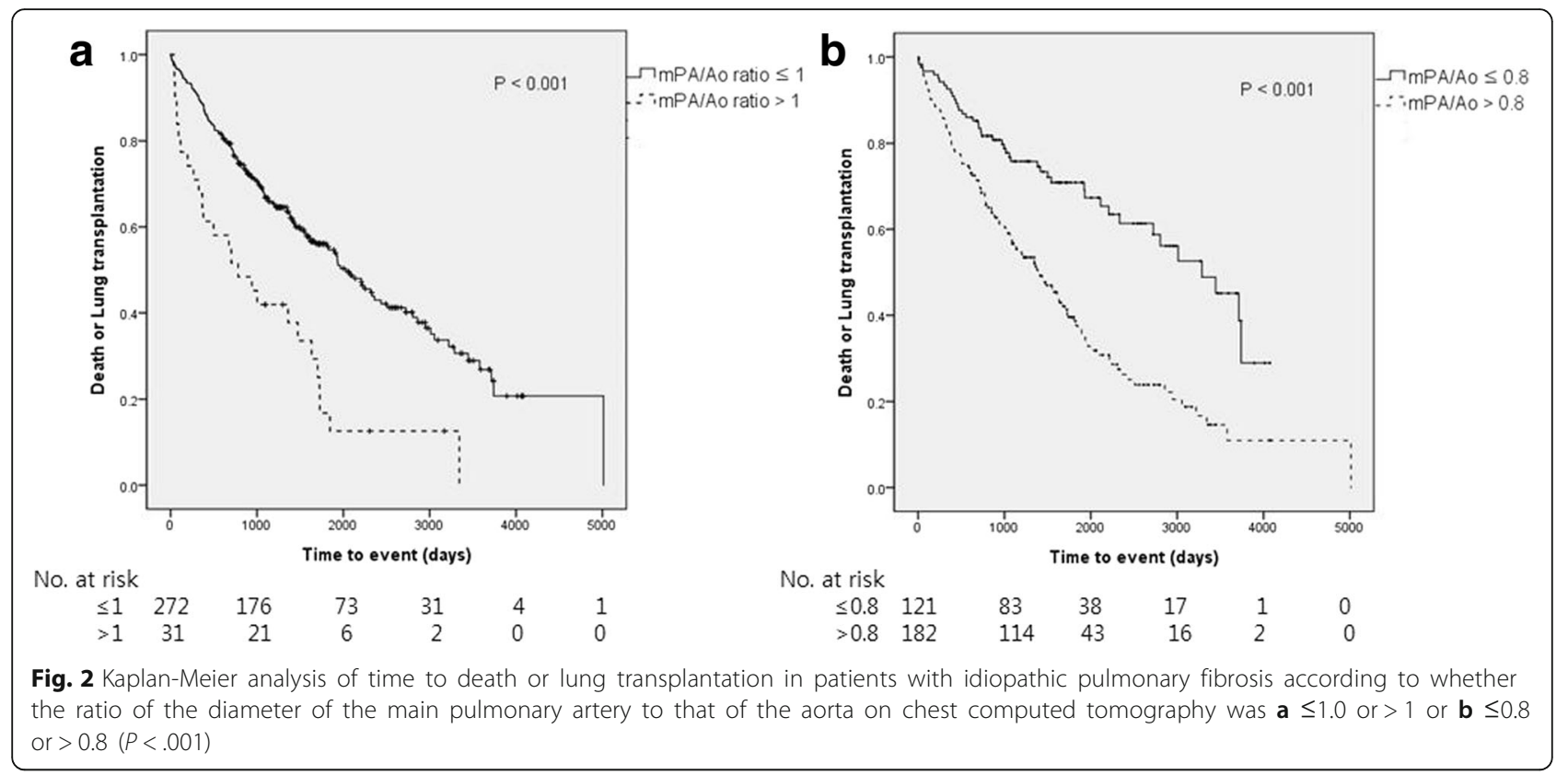

We found a statistically difference in the GAP score between the group with an $\mathrm{mPA} / \mathrm{Ao}$ ratio $>1.0$ and the group with an $\mathrm{mPA} /$ Ao ratio $\leq 1.0$ in univariate analysis. The components of the GAP score, i.e., sex, age, FVC \% predicted, and DLco \% predicted, have been validated as prognostic factors in patients with IPF [17, 31-33]. Furthermore, in our study, the mPA/Ao ratio was associated with a poor outcome, including death or lung transplantation, in patients with IPF. Overall, our findings suggest that the $\mathrm{mPA} / \mathrm{Ao}$ ratio could be used to predict the prognosis of IPF and the associated risks, which is in agreement with previous reports. Shin et al. reported that an $\mathrm{mPA} /$ Ao ratio $>1$ was associated with poor outcomes in Western patients with IPF and that calculation of the $\mathrm{mPA} / \mathrm{Ao}$ ratio on chest CT might be used for risk stratification in these patients [14]. Similar results have been reported in patients with COPD. A high mPA/Ao ratio was associated with severe exacerbations of COPD [34] and was an independent predictor of mortality [35]. Given the results in patients with COPD, a high $\mathrm{mPA} / \mathrm{Ao}$ ratio in patients with IPF could be related to acute exacerbation in addition to the possibility of $\mathrm{PH}$.

We also investigated the prognostic value of the $\mathrm{mPA} / \mathrm{Ao}$ ratio when based on a cutoff of 0.8 . An $\mathrm{mPA} /$ Ao ratio $>0.8$ was also associated with a worse outcome than an $\mathrm{mPA} / \mathrm{Ao}$ ratio $\leq 0.8$ in patients with IPF. One Korean study reported a mean $\mathrm{mPA} / \mathrm{Ao}$ ratio of 0.87 and another reported an $\mathrm{mPA} / \mathrm{Ao}$ ratio $>0.8$ to be a risk factor for exacerbation of COPD $[15,16]$. These results can be explained by differences in the body mass index, lifestyle factors, and/or the distribution of mPA/Ao values in the study populations. Therefore, a borderline mPA/Ao ratio in a Korean patient with IPF may have adverse clinical implications in terms of the prognosis. Our findings suggest that patients with IPF and an $\mathrm{mPA} /$ Ao ratio $>0.8$ require close observation, including short-term follow-up evaluation with chest CT and PFT results as well as early consideration for lung transplantation in view of their poor prognosis.

This study had several limitations. The first is that it was conducted retrospectively at a single center. Furthermore, some data that might have influenced the results were missing, and several examinations, including transthoracic echocardiography and 6-min walking distance, were not performed in all patients. Second, there might have been some variation in the $\mathrm{mPA}$ and Ao measurements obtained on chest $\mathrm{CT}$ depending on the reviewer. However, we tried to overcome this limitation by having two reviewers measure the diameters of the $\mathrm{mPA}$ and Ao independently. Third, the proportion of patients who underwent transplantation was relatively high at our center, which could have introduced a degree of bias when evaluating the outcome. Fourth, we did not perform right heart catheterization, so it was not possible to correlate the hemodynamics with the $\mathrm{mPA} / \mathrm{Ao}$ ratio on $\mathrm{CT}$ in detail. Nevertheless, our study also has some strengths, in that it shows that a high $\mathrm{mPA} / \mathrm{Ao}$ ratio could be a prognostic factor in Asian patients with IPF and that a borderline $\mathrm{mPA} /$ Ao value could be clinically meaningful in these patients. Our findings may be relevant to patients when they are initially diagnosed with IPF, although prospective studies are needed for validation. 


\section{Conclusions}

We have identified that the $\mathrm{mPA} /$ Ao ratio on chest $\mathrm{CT}$ at the time of initial diagnosis of IPF has prognostic implications. An mPA/Ao ratio $>1$ was associated with poor outcome in patients with IPF. In addition, an mPA/Ao ratio $>0.8$ can be considered an early adverse prognostic factor in these patients. We suggest that the diameters of the mPA and Ao should be measured on chest CT at the time of initial diagnosis of IPF and that patients found to have a higher $\mathrm{mPA} /$ Ao ratio be kept under close observation.

\section{Abbreviations \\ Ao: Aorta; Cl: Confidence interval; CT: Computed tomography; $\mathrm{DL}_{c o}$ : Diffusing capacity of the lung for carbon dioxide; $\mathrm{FEV}_{1}$ : Forced expiratory volume in $1 \mathrm{~s}$; HR: Hazard ratio; IPF: Idiopathic pulmonary fibrosis; IQR: Interquartile range; mPA: Main pulmonary artery; PH: Pulmonary hypertension}

\section{Acknowledgements}

Not applicable

\section{Funding}

This study has received no funding.

\section{Availability of data and materials}

The datasets used and/or analysed during the current study are available from the corresponding author on reasonable request.

\section{Authors' contributions}

SYK had full access to all of the data in the study, and takes responsibility for the integrity of the data and the accuracy of the data analysis. JSC and SYK contributed substantially to the study design, data analysis and interpretation, and the writing of the manuscript. All authors read and approved the final manuscript.

\section{Ethics approval and consent to participate}

This study was approved by Institutional review board approval for Severance Hospital (IRB IRB 4-2017-1219). The need for informed consent was waived.

\section{Consent for publication}

Not applicable

\section{Competing interests}

The authors declare that they have no competing interests.

\section{Publisher's Note}

Springer Nature remains neutral with regard to jurisdictional claims in published maps and institutional affiliations.

Received: 28 October 2018 Accepted: 2 April 2019

Published online: 18 April 2019

\section{References}

1. Lettieri CJ, Nathan SD, Barnett SD, Ahmad S, Shorr AF. Prevalence and outcomes of pulmonary arterial hypertension in advanced idiopathic pulmonary fibrosis. Chest. 2006;129(3):746-52.

2. Raghu G, Collard HR, Egan JJ, Martinez FJ, Behr J, Brown KK, Colby TV Cordier JF, Flaherty KR, Lasky JA, et al. An official ATS/ERS/JRS/ALAT statement: idiopathic pulmonary fibrosis: evidence-based guidelines for diagnosis and management. Am J Respir Crit Care Med. 2011;183(6): $788-824$.

3. Patel NM, Lederer DJ, Borczuk AC, Kawut SM. Pulmonary hypertension in idiopathic pulmonary fibrosis. Chest. 2007;132(3):998-1006.
4. Hoeper MM, Bogaard HJ, Condliffe R, Frantz R, Khanna D, Kurzyna M, Langleben D, Manes A, Satoh T, Torres F, et al. Definitions and diagnosis of pulmonary hypertension. J Am Coll Cardiol. 2013;62(25 Suppl):D42-50.

5. Janda S, Shahidi N, Gin K, Swiston J. Diagnostic accuracy of echocardiography for pulmonary hypertension: a systematic review and meta-analysis. Heart. 2011:97(8):612-22.

6. Wang YC, Huang CH, Tu YK. Pulmonary hypertension and pulmonary artery acceleration time: a systematic review and meta-analysis. J Am Soc Echocardiogr. 2018;31(2):201-10.

7. Arcasoy SM, Christie JD, Ferrari VA, Sutton MS, Zisman DA, Blumenthal NP, Pochettino A, Kotloff RM. Echocardiographic assessment of pulmonary hypertension in patients with advanced lung disease. Am J Respir Crit Care Med. 2003:167(5):735-40

8. Nathan SD, Shlobin OA, Barnett SD, Saggar R, Belperio JA, Ross DJ, Ahmad S, Saggar R, Libre E, Lynch JP 3rd, et al. Right ventricular systolic pressure by echocardiography as a predictor of pulmonary hypertension in idiopathic pulmonary fibrosis. Respir Med. 2008;102(9):1305-10.

9. Alkukhun L, Wang XF, Ahmed MK, Baumgartner M, Budev MM, Dweik RA, Tonelli AR. Non-invasive screening for pulmonary hypertension in idiopathic pulmonary fibrosis. Respir Med. 2016;117:65-72.

10. Kam JC, Pi J, Doraiswamy V, Elnahar Y, Abdul-Jawad S, DeBari VA, Klukowicz AJ, Shamoon F, Miller RA. CT scanning in the evaluation of pulmonary hypertension. Lung. 2013;191(4):321-6.

11. McCall RK, Ravenel JG, Nietert PJ, Granath A, Silver RM. Relationship of main pulmonary artery diameter to pulmonary arterial pressure in scleroderma patients with and without interstitial fibrosis. J Comput Assist Tomogr. 2014;38(2):163-8.

12. Tan RT, Kuzo R, Goodman LR, Siegel R, Haasler GB, Presberg KW. Utility of $\mathrm{CT}$ scan evaluation for predicting pulmonary hypertension in patients with parenchymal lung disease. Medical College of Wisconsin lung transplant group. Chest. 1998;113(5):1250-6

13. $\mathrm{Ng}$ CS, Wells AU, Padley SP. A CT sign of chronic pulmonary arterial hypertension: the ratio of main pulmonary artery to aortic diameter. J Thorac Imaging. 1999;14(4):270-8.

14. Shin S, King CS, Puri N, Shlobin OA, Brown AW, Ahmad S, Weir NA, Nathan SD. Pulmonary artery size as a predictor of outcomes in idiopathic pulmonary fibrosis. Eur Respir J. 2016;47(5):1445-51.

15. Lee SH, Kim YJ, Lee HJ, Kim HY, Kang YA, Park MS, Kim YS, Kim SK, Chang J Jung JY. Comparison of CT-determined pulmonary artery diameter, aortic diameter, and their ratio in healthy and diverse clinical conditions. PLoS One. 2015;10(5):e0126646.

16. Chung KS, Kim YS, Kim SK, Kim HY, Lee SM, Seo JB, Oh YM, Jung JY, Lee SD. Functional and prognostic implications of the Main pulmonary artery diameter to aorta diameter ratio from chest computed tomography in Korean COPD patients. PLoS One. 2016;11(5):e0154584.

17. Ley B, Ryerson CJ, Vittinghoff E, Ryu JH, Tomassetti S, Lee JS, Poletti V, Buccioli M, Elicker BM, Jones KD, et al. A multidimensional index and staging system for idiopathic pulmonary fibrosis. Ann Intern Med. 2012;156(10):684-91.

18. Coultas DB, Zumwalt RE, Black WC, Sobonya RE. The epidemiology of interstitial lung diseases. Am J Respir Crit Care Med. 1994:150(4):967-72.

19. Raghu G, Weycker D, Edelsberg J, Bradford WZ, Oster G. Incidence and prevalence of idiopathic pulmonary fibrosis. Am J Respir Crit Care Med. 2006;174(7):810-6.

20. American Thoracic Society/European Respiratory Society International Multidisciplinary Consensus Classification of the Idiopathic Interstitial Pneumonias. This joint statement of the American Thoracic Society (ATS), and the European Respiratory Society (ERS) was adopted by the ATS board of directors, June 2001 and by the ERS Executive Committee, June 2001 Am J Respir Crit Care Med. 2002;165(2):277-304.

21. Ley B, Collard HR, King TE Jr. Clinical course and prediction of survival in idiopathic pulmonary fibrosis. Am J Respir Crit Care Med. 2011;183(4):431-40.

22. Fell CD, Martinez FJ. The impact of pulmonary arterial hypertension on idiopathic pulmonary fibrosis. Chest. 2007;131(3):641-3.

23. Nathan SD, Noble PW, Tuder RM. Idiopathic pulmonary fibrosis and pulmonary hypertension: connecting the dots. Am J Respir Crit Care Med. 2007:175(9):875-80.

24. Pitsiou G, Papakosta D, Bouros D. Pulmonary hypertension in idiopathic pulmonary fibrosis: a review. Respiration. 2011:82(3):294-304.

25. Taleb M, Khuder S, Tinkel J, Khouri SJ. The diagnostic accuracy of Doppler echocardiography in assessment of pulmonary artery systolic pressure: a meta-analysis. Echocardiography (Mount Kisco, NY). 2013;30(3):258-65. 
26. Greiner S, Jud A, Aurich M, Hess A, Hilbel T, Hardt S, Katus HA, Mereles D. Reliability of noninvasive assessment of systolic pulmonary artery pressure by Doppler echocardiography compared to right heart catheterization: analysis in a large patient population. J Am Heart Assoc. 2014;3(4):e001103.

27. Modrykamien AM, Gudavalli R, McCarthy K, Parambil J. Echocardiography, 6minute walk distance, and distance-saturation product as predictors of pulmonary arterial hypertension in idiopathic pulmonary fibrosis. Respir Care. 2010;55(5):584-8.

28. Devaraj A, Wells AU, Meister MG, Corte TJ, Wort SJ, Hansell DM. Detection of pulmonary hypertension with multidetector $C T$ and echocardiography alone and in combination. Radiology. 2010;254(2):609-16.

29. Iyer AS, Wells JM, Vishin S, Bhatt SP, Wille KM, Dransfield MT. CT scanmeasured pulmonary artery to aorta ratio and echocardiography for detecting pulmonary hypertension in severe COPD. Chest. 2014;145(4):824-32.

30. Schmidt HC, Kauczor HU, Schild HH, Renner C, Kirchhoff E, Lang P, Iversen S, Thelen M. Pulmonary hypertension in patients with chronic pulmonary thromboembolism: chest radiograph and $\mathrm{CT}$ evaluation before and after surgery. Eur Radiol. 1996;6(6):817-25.

31. Kim ES, Choi SM, Lee J, Park YS, Lee CH, Yim JJ, Yoo CG, Kim YW, Han SK, Lee SM. Validation of the GAP score in Korean patients with idiopathic pulmonary fibrosis. Chest. 2015;147(2):430-7.

32. Ryerson CJ, Vittinghoff E, Ley B, Lee JS, Mooney JJ, Jones KD, Elicker BM, Wolters PJ, Koth LL, King TE Jr, et al. Predicting survival across chronic interstitial lung disease: the ILD-GAP model. Chest. 2014;145(4):723-8.

33. Ley B, Bradford WZ, Weycker D, Vittinghoff E, du Bois RM, Collard HR. Unified baseline and longitudinal mortality prediction in idiopathic pulmonary fibrosis. Eur Respir J. 2015;45(5):1374-81.

34. Wells JM, Washko GR, Han MK, Abbas N, Nath H, Mamary AJ, Regan E, Bailey WC, Martinez FJ, Westfall E, et al. Pulmonary arterial enlargement and acute exacerbations of COPD. N Engl J Med. 2012;367(10):913-21.

35. Shin S, King CS, Brown AW, Albano MC, Atkins M, Sheridan MJ, Ahmad S, Newton KM, Weir N, Shlobin OA, et al. Pulmonary artery size as a predictor of pulmonary hypertension and outcomes in patients with chronic obstructive pulmonary disease. Respir Med. 2014;108(11):1626-32.

Ready to submit your research? Choose BMC and benefit from:

- fast, convenient online submission

- thorough peer review by experienced researchers in your field

- rapid publication on acceptance

- support for research data, including large and complex data types

- gold Open Access which fosters wider collaboration and increased citations

- maximum visibility for your research: over $100 \mathrm{M}$ website views per year

At $\mathrm{BMC}$, research is always in progress.

Learn more biomedcentral.com/submissions 